\title{
EL PRINCIPIO DE PRESUNCIÓN DE INOCENCIA FRENTE A LA APLICACIÓN DEL PROCEDIMIENTO ABREVIADO EN EL ECUADOR
}

\author{
Hector Mosquera Pazmiño ${ }^{1}$, Eduardo González Romero² y Ángel Barrios Miranda ${ }^{3}$. \\ \{hector.mosquerap, abel.gonzalezr, angel.barriosm\}@ug.edu.ec \\ https://orcid.org/0000-0001-7090-1056 \\ https://orcid.org/0000-0003-3229-5328 \\ https://orcid.org/0000-0003-3056-4416 \\ Universidad de Guayaquil \\ Guayaquil-Ecuador
}

Recibido (08/06/20), Aceptado (23/06/20)

\begin{abstract}
Resumen: El este trabajo se presenta el análisis del procedimiento abreviado contemplado en el Código Orgánico Integral Penal del Ecuador, el cual tiene como naturaleza jurídica, la simplificación de las etapas procesales en una única audiencia de juicio, a raíz de que el imputado acepta lo que se le atribuye, y consecuentemente recibe una reducción en la pena que corresponda. Si bien es cierto, aun cuando existe una apología acerca de que dicho procedimiento se fundamenta en la espontaneidad y consentimiento del procesado, tampoco es menos cierto que existe una coacción psicológica que ubica al justiciable en un estado de indefensión, en cuanto a la decisión sobre la cual estará en juego su libertad, puesto que existe una negociación jurídica con respecto al derecho a la defensa y al debido proceso, los cuales proclama de manera expresa la Constitución del Ecuador y en los Tratados Internaciones de Derechos Humanos a los cuales estamos adheridos como Estado.
\end{abstract}

Palabras Clave: Procedimiento abreviado, principio de presunción de inocencia, debido proceso, derecho a la defensa.

\section{THE PRINCIPLE OF THE PRESUMPTION OF INNOCENCE AGAINST THE APPLICATION OF THE ABBREVIATED PROCEDURE IN ECUADOR}

\begin{abstract}
In this work, the analysis of the abbreviated procedure contemplated in the Organic Comprehensive Organic Code of Ecuador is presented, which has as its legal nature, the simplification of the procedural stages in a single trial hearing, a root of which the accused accepts what is attributes to it, and consequently receives a reduction in the corresponding penalty. Although it is true, even when there is an apology that said procedure is based on the spontaneity and consent of the process, it is also true that there is a psychological coercion that places the defendant in a state of defenselessness, regarding the decision on which will be at stake their freedom, since there is a legal negotiation regarding the right to defense and due process, any expressly proclaims the Constitution of Ecuador and in the International Human Rights Treaties to which we are adhered as State.
\end{abstract}

Keywords: Abbreviated procedure, principle of presumption of innocence, due process, right to defense. 


\section{I.INTRODUCCIÓN}

El sistema jurídico-procesal del Ecuador se caracteriza por ser objeto de duras críticas por parte del conglomerado social, así como por aquellos conocedores del derecho. Teóricamente el ámbito procesal ha dado sustanciales pasos de progreso, que va conjuntamente de la mano con los grandes sistemas jurídicos europeos, sin embargo, es menester recalcar que al final del día, este sistema termina siendo atentado en cuanto a su naturaleza jurídica, y esto se ve reflejado en los altos índices delincuenciales que atentan contra la seguridad social, todo esto debido a la proliferación de la corrupción que corrompe hasta el más etéreo sistema jurídico contemporáneo. Sin embargo, aun cuando en toda persona existan indicios de elementos de convicción que podrían acarrear su culpabilidad total en el hecho que se le atribuye, deberán de respetárseles todos aquellos derechos y garantías proclamadas en los distintos cuerpos normativos nacionales e internacionales, en donde uno de los fundamentales es aquel que posibilita su integridad física y mental, y con ello se refiere al principio jurídico-fundamental de la presunción de inocencia, es decir, el estatus jurídico que debe y deberá mantener toda persona, la cual esté inmiscuida dentro de un procedimiento determinado, con miras a establecer su responsabilidad y por consecuente imponer la sanción que corresponda, pero hasta que ello suceda, se deberá actuar conforme a las reglas del debido proceso del justiciable. Las diferentes causas penales que se presentan en el despacho del juzgador, se sustancian bajo distintos procedimientos que contempla el Código orgánico Integral Penal, entre ellos el más conocido y aplicado es el Procedimiento ordinario que consta de las etapas de instrucción fiscal, audiencia preparatoria de juicio y la audiencia de juicio. Sin embargo en los último años surgieron un grupo de procedimientos especiales, entre los cuales está el procedimiento abreviado, que entra a regir como un medio alternativo del procedimiento ordinario en cuanto a la sustanciación de las causas penales bajo ciertas condiciones o reglas normativas, esto debido a la celeridad con la que actúa, puesto que concentra todas las etapas procesales en una única audiencia, pero lo crítico de este nuevo procedimiento, es su contexto jurídico puesto que el justiciable, previa intervención del fiscal, consiente en cuanto a los hechos que se le imputa y como beneficio recibe una reducción de hasta un tercio de la pena mínima impuesta al tipo penal que se le atribuye, es decir, que existe una vulneración a principios constitucionales como el de la presunción de inocencia, debido proceso, tutela judicial efectiva y el de no autoincriminación.

\section{II.DESARROLLO}

La presunción de inocencia corresponde por naturaleza a toda persona objeto de imputabilidad por parte de órganos estatales competentes para ejercer la administración de justicia. La situación jurídica de presunción de inocencia no es un factor relativamente nuevo, puesto que posee antecedentes en distintos documentos de carácter supranacional con efecto vinculante en diversos países del mundo.

El más destacable de ellos es sin lugar a duda aquel imperativo de presunción de inocencia inmiscuido en la Declaración Universal de los Derechos del Hombre [1] particularmente en su artículo 11.1 el cual establece que toda persona acusada de delito tiene derecho a que se presuma su inocencia mientras no se pruebe su culpabilidad, conforme a la ley y en juicio público en el que se le hayan asegurado todas las garantías necesarias para su defensa.

De esta manera se puede determinar que, de manera inexorable toda persona mantiene su estatus jurídico de inocencia hasta que no se establezca en su contra las pruebas de convicción suficiente que conlleven a su responsabilidad en cualquier falta cometida, ya sea de acción u omisión, siempre y cuando dichas pruebas o elementos de convicción hayan sido encaminadas por el sendero de la ley y el debido proceso del imputado.

De igual manera en la Convención Americana sobre Derechos Humanos [2], su artículo 8.2 establece que toda persona inculpada de delito tiene derecho a que se presuma su inocencia mientras no se establezca legalmente su culpabilidad.

Es menester que mencionemos uno de los documentos de carácter internacional más citados sobre el tema, es el texto de la Observación General Número 13 [3], del Comité de Derechos Humanos en el que se señala que tomando en cuenta la presunción de inocencia, la carga de la prueba recae sobre la acusación y el acusado tiene el beneficio de la duda. No puede suponerse a nadie culpable a menos que se haya demostrado que la acusación esté fuera de toda duda razonable. Además, la presunción de inocencia implica el derecho a ser tratado de conformidad con este principio. Por lo tanto todas las autoridades públicas tienen la obligación de no prejuzgar el resultado del proceso.

Lo antes mencionado determina, como el presunto infractor deberá ser tratado como tal en todas las etapas procesales del juicio, aun cuando los elementos de cargo puedan contemplar indicios de responsabilidad en la falta que se le imputa, puesto que de conformidad con este principio la carga de la prueba recae sobre la acusación mientras que el acusado goza del beneficio de la duda hasta que no se le imponga una sentencia conde- 
natoria que determine lo contrario.

Particularmente la legislación Ecuatoriana ha sido muy destacada por incorporar innumerables contextos imperativos de carácter internacional y que a su vez gozan de garantía y seguridad jurídica, y la presunción de inocencia no ha sido la excepción, puesto que en la Constitución de la República del Ecuador [4] se establece que se presumirá la inocencia de toda persona, y se tratará como tal mientras no se declare su responsabilidad mediante resolución firme o sentencia ejecutoriada.

La Carta Magna [4] es muy directa en cuanto a determinar que lo único que podrá terminar una variación de carácter jurídico en la presunción de inocencia, es una resolución firme o sentencia ejecutoriada, pero a esto deberá de añadírsele además, de que dicha sentencia o resolución firme deberán ser obtenida de conformidad con la normativa del debido proceso así como respetando los Tratados y Convenios Internacionales de Derechos Humanos, puesto que de no ser así, carecerán de eficacia jurídica y el juzgador podrá ser objeto de responsabilidad penal por el tipo penal de prevaricato el cual se encuentra contemplado en el artículo $268 \mathrm{del}$ Código Orgánico Integral Penal [5].

El Código Orgánico Integral Penal [5] en el artículo 5 numeral 4 también manifiesta de manera expresa que sin distinción alguna, toda persona conserva su estado de inocencia, mientras no se ejecute una sentencia que determine su culpabilidad.

Por último, en lo que respecta a los sistemas penales contemporáneos, el principio jurídico-fundamental de presunción de inocencia se constituye como un derecho y una garantía fundamental e irrenunciable para las personas, específicamente de aquellas que se ven imputadas en la comisión de un hecho fáctico punible sancionado por la Dogmática Jurídico-Penal. Por consiguiente, esta institución procesal que fundamenta el cimiento básico del sistema penal acusatorio vigente, merece los más escudriñados y profundo análisis doctrinales y universitarios para de esta manera, poder alcanzar la efectividad plena del sistema de administración de justicia.

\section{A.EI debido proceso en el Ecuador}

Este derecho constitucional y de carácter jurídicoprocesal se contempla en nuestra Constitución de la República del Ecuador del 2008 [4], particularmente en su artículo 76 en donde reconoce la inexorable aplicación del debido proceso como el sendero sobre el cual se funda la administración de justicia en cuanto a la determinación de la responsabilidad administrativa, civil o penal de una persona.

El debido proceso tiende a efectivizar el estatus de la persona a la cual se le atribuye la comisión de una in- fracción o falta [6], de tal manera que a través del debido proceso se plantea una garantía para con el imputado en tanto y cuanto, le permite poder adherirse al mismo para hacer respetar sus derechos y garantías constitucionales a lo largo de las distintas etapas procesales.

Es posible afirmar que el derecho al debido proceso se lo concibe como un intrínseco conjunto de garantías y derechos de carácter constitucional y supranacional [7], que le asisten a una persona procesada frente a cualquier tipo de vulneración procesal, frente al ius punnendi, es decir, el poder punitivo que detenta el Estado en cuanto a la imposición de penas por el cometimiento de infracciones penales. El debido proceso constituye un principio rector, de sustancial importancia, de amplia trayectoria procesal, incorporado tanto en la Constitución como en los Tratados Internacionales de Derechos Humanos [1].

\section{B.El Procedimiento Abreviado en la Legislación Na- cional}

El procedimiento abreviado surge como un procedimiento especial para la aplicación de la administración de justicia, mediante la expedición del Código de Procedimiento Penal [5], publicado en el Registro Oficial Nro. 360 del 13 de Enero del año 2000. De acuerdo a lo mencionado se concibe como un procedimiento especial puesto que se excluye de la normativa procesal aplicable al procedimiento ordinario, sin embargo el mencionado procedimiento especial no cumple con lo pertinente de otros procedimientos especiales que contempla el Código Orgánico Integral Penal, en sus artículos del 634 en adelante, y a su vez dicho procedimiento en razón de la persona acusada, no es más que un negocio jurídico que celebra el fuero del ministerio público, con el imputado y con la venia o aprobación del juzgador [8].

Es importante que las autoridades encargadas de administrar justicia comprendan que este tipo de procedimiento especial, al entrar de una u otra manera a reemplazar la sujeción del imputado al procedimiento ordinario, deberá de ser aplicado con el debido cuidado procesal de no vulnerar en el camino los derechos y garantías constitucionales del justiciable, ya que acarreará un error insubsanable para el procesado.

Los procedimientos especiales aplicables son aquellos que entran a reemplazar en determinados hechos el esquema normativo aplicable al procedimiento ordinario. En otras palabras y para una mayor comprensión del lector, me es indispensable brindar una doctrinal conceptualización de los que se entiende por procedimiento abreviado.

El hecho de que a través de este proceso se varia el 
curso del procedimiento ordinario aplicable, para encaminarse por el sendero de este tipo de procedimiento especial y aún más relevante es el hecho de que para hacérselo se necesitará la capacidad y consentimiento absoluto de la parte procesal legalmente facultada en todos sus sentidos, la misma que se sujetara al procedimiento abreviado, y que a su vez de manera motivada en la mayoría de los casos, consiente en su aplicabilidad por el hecho de aquellos mal llamados acuerdos que giraran en torno a los hechos y a la pena impuesta a dicho procesado, esto con el único fin de anticipar de manera abrupta el debido proceso que legalmente le corresponde a toda persona involucrada dentro de un proceso penal, la cual en el mismo, podrá presentar las pruebas de descargo suficiente para atenuar, eximir o extinguir totalmente la infracción o el hecho que se le atribuye, sin embargo con el sometimiento del procesado al procedimiento abreviado, consiente en los hechos fácticos que se le atribuyen como un medio de escape tanto para él, como para el fuero del fiscal y del mismo administrador de justicia, en tanto y cuanto se exhortan de seguir con las etapas que corresponde dentro de un procedimiento ordinario, sino que más bien el proceso se da por finalizado en una sola audiencia del procedimiento abreviado, en donde el justiciable de manera anticipada acepta su presunta responsabilidad en el hecho que se le imputa, con el objetivo previamente pactado, de la reducción de hasta un tercio de la pena mínima aplicable al tipo penal que presuntamente perpetro el procesado.

Ahora si bien es cierto, la aplicación de dicho procedimiento apuntó de manera positiva en ciertos enfoques que mencionan las líneas citadas anteriormente, pero tampoco es menos cierto el hecho de que este procedimiento especial ha sido objeto de innumerables criticas de juristas y docentes universitarios, los cuales hallan falencias en la aplicación del mismo, en cuanto a la vulneración del principio al debido proceso para con el justiciable, más concretamente me refiero al principio de la presunción de inocencia para con el imputado, puesto que este al verse inmiscuido en tal situación en donde peligra su libertad como derecho fundamental del ser humano, en la mayoría de los casos opta por someterse a dicho procedimiento, esto debido a la hegemonía e inconstitucional postura con la que muchas veces se muestran los fiscales en las distintas etapas procesales, más concretamente en aquellas en donde tiene la obligación de acuerdo con el articulo 5 numeral 21 de Código Orgánico Integral Penal, en donde establece que es obligación del fiscal la presentación de pruebas tanto de cargo como de descargo, es decir aquellas que podrían eximir, atenuar o extinguir la responsabilidad penal del procesado, sin embargo esto no sucede en la praxis de la legislación penal ecuatoriana puesto que el señor fiscal en la mayoría de sus casos y en abuso de sus atribuciones de justicia, aun antes de que se lleve a cabo la respectiva audiencia de formulación de cargos, condena moralmente la postura del procesado, violentando la presunción de su inocencia de toda persona acusada.

\section{C.Reglas del Procedimiento Abreviado}

Para esta explicación el artículo 635 del Código Orgánico Integral Penal [5], nos describe en forma clara que el procedimiento abreviado deberá sustanciarse de conformidad con las siguientes reglas:

-Las infracciones sancionadas con pena máxima privativa de libertad de hasta diez años, son susceptibles de procedimiento abreviado.

-La propuesta de la o el fiscal podrá presentarse desde la audiencia de formulación de cargos hasta la audiencia de evaluación y preparatoria de juicio.

- La persona procesada deberá consentir expresamente tanto la aplicación de este procedimiento como la admisión del hecho que se le atribuye.

-La o el defensor público o privado acreditará que la persona procesada haya prestado su consentimiento libremente, sin violación a sus derechos constitucionales.

-La existencia de varias personas procesadas no impide la aplicación de las reglas del procedimiento abreviado.

-En ningún caso la pena por aplicar podrá ser superior o más grave a la sugerida por la o el fiscal.

En lo que respecta al primer numeral, ha existido una variación puesto que el antiguo Código de Procedimiento Penal solo permitía que se sujeten a este procedimiento, las infracciones sancionadas hasta con 5 años de pena privativa de libertad, mientras que con la llegada del nuevo Código Orgánico Integral Penal aprobado y publicado en el registro oficial N. 180 del 10 de febrero de 2014, este cuerpo legal determinó que en cuanto a las reglas de admisibilidad para el procedimiento abreviado serán susceptibles aquellos delitos cuyo pena pase de los 10 años, esto tiende a ser un punto de critica puesto que de acuerdo a la dogmática jurídico-penal por regla general, aquellos delitos cuya pena privativa de libertad no supera los 5 años, se los puede considerar delitos culposos, mientras que aquellos que superan esta pena, es decir, aquellos que superan los 5 años, se los considera delitos dolosos.

Pese a aquello y como lo manifiesta el Dr. Ricardo Vaca Andrade [9], el cual muestra su disconformidad con esta mecánica, pues, sería restrictiva y poco severa en el caso de que existan personas procesadas, por 
ejemplo, por el tipo penal de narcotráfico, que hayan sido sorprendidas bajo delito flagrante y que se cuenten con pruebas de cargo incontrovertibles e incluso que estén dispuestas a someterse a este procedimiento y entregando como datos fundamentales como parte de la negociación del acuerdo y de la pena.

El siguiente punto, objeto de crítica es aquel en donde como se lo determina en el numeral 2 del artículo 635 del COIP corresponde al fiscal la propuesta al procesado o a su defensor, la posibilidad de someterse al procedimiento abreviado, sin embargo este proceso carece de un filtro que determine objetivamente la forma en la cual se le exprese al procesado la posibilidad de someterse a este tipo de procedimiento especial, particularmente esta etapa recae sobre su defensor el cual tiene la obligación de darle a conocer a su defendido de forma sencilla, todo lo que respecta al sometimiento de este proceso, pero este punto tiende a poder ser objeto de una coacción psicológica por parte del defensor público o privado y más aún por parte del fiscal, la coacción psicológica inevitablemente provoca una sumisión mental hacia la psiquis del procesado, este tipo de coacción es ejercida cuando una persona debida a su atribuibilidad particular que la ubica en un estatus superior al de la persona vulnerada, produce lo que en materia de Psicología, se conoce como Psicología Inversa, entendámosla como una técnica de persuasión que tiene por objetivo influir en el comportamiento o conducta humana para que una persona haga o consienta en determinado acto, afectando directamente o indirectamente a su reactancia cognitiva, puesto que al ubicarlo en una posición negativa en cuanto a su libertad individual, este se ve en la necesidad de ser ingenuamente permisible en cuanto a acuerdos que se le puedan plantear, esto debido muchas veces, a la falta de compresión o capacidad para poder comprender lo que realmente sucede a su alrededor y las formas de las cuales se puede adherir para conseguir el resultado deseado, sin necesidad de verse inmiscuido en un tipo de coacción psicológica que cause colateralmente un daño en garantías y principios jurídico-fundamentales.

Prueba de lo mencionado en líneas anteriores, es el principio procesal de adquisición, el cual le permite a la persona procesada hacerse de prueba que se presente de manera valida y que pudiere beneficiarle en cuando a un factor de descargo en la responsabilidad penal que se le esté imputando, el principio de adquisición considera irrelevante el hecho de quien es el que aporta la prueba que pudiere ser beneficiosa para la persona procesada, siempre que se la produzca de manera legal. En este sentido, este principio se encuentra directamente relacionado con el principio de oportunidad para la prueba, así como el de contradicción, lo que garantizaría el derecho a la defensa de las partes, así como para la valoración en su conjunto de la carga probatoria por parte del administrador de justicia, y por consecuente llegar a la veracidad procesal para la realización de la justicia, de igual manera en este principio también se toma en consideración otros principios procesales como son: la inmediación, publicidad, oralidad, unidad de la prueba.

La sumisión del procesado al procedimiento abreviado no permite que se produzca todo lo antes mencionado, puesto que el justiciable renuncia de una u otra forma, con la intervención previa de una coacción psicológica, a su derecho constitucional de ser juzgado en un Juicio que se sustancie bajo la normativa aplicable en el procedimiento ordinario, ante los jueces competentes, tramitado en todas sus etapas pre-procesales y procesales, y con respeto estricto a las garantías expresas del debido proceso. Por lo tanto, aceptar la participación del procesado, en la infracción que se le atribuye a una persona, no involucra aceptación de responsabilidad, ya que ello vendría a ser autoincriminación, y de esta manera se atenta directamente el principio constitucional de la presunción de inocencia de las personas, determinado en el artículo 77 literal c de nuestra Carta Magna, así como lo expresado en el artículo 5 numeral 8 del COIP en donde se prohíbe la autoincriminación sobre hechos que podrían acarrear anticipadamente la responsabilidad penal de una persona.

Otro punto de análisis del artículo 635 del COIP es el que determina el numeral 6 , en donde una vez que la persona procesada, declara favorable el hecho atribuido en su contra, entre la Fiscalía y el procesado, posiblemente el defensor público o privado accionando a nombre de su defendido, acuerda una pena inferior a la prevista en la ley penal para la infracción que se le imputa a su defendido; hecho por el cual, pasaría a una segunda etapa, que es buscar la aprobación del juzgador. Una vez que conozca el acuerdo el Juez competente, este no podrá imponer una pena superior ni más grave que la sugerida por el señor Fiscal, es decir, que con el consentimiento que haga la persona procesada sobre la ejecución del hecho fáctico que se le atribuye, el fiscal a cambio le garantizará que el Juez le imponga la pena acordada.

De esta manera el procesado evita someterse a un juicio ordinario, exhortándose a sí mismo del derecho de ser sometido a un juicio de culpabilidad, en donde de manera pública, motivada, oral y contradictoria se lo juzgue, en base al principio de atribuibilidad que incluye los sub-juicios de imputabilidad y culpabilidad. De igual manera desde el momento en que un imputado es liberado del juez competente por la legislación penal 
para la determinación de su culpabilidad, para someterlo a otro juzgador incompetente para tal determinación, se violenta el derecho de defensa y a través de una resolución firme o sentencia, se le impone una pena inconstitucional, puesto que solamente el individuo imputable que ha sido debidamente expuesto y declarado como tal por los órganos jurisdiccionales siguiendo el procedimiento previamente establecido en la ley, es el que puede ser constitucionalmente considerado y reconocido legalmente como culpable, caso contrario dicho actúa carecerá de eficacia jurídica [8].

\section{D.Rol de la Defensoría Pública frente a la aplicación del Procedimiento Abreviado}

La Defensoría pública es el órgano autónomo de la Función Judicial que tiene como objetivo principal garantizar el acceso directo y eficaz de las personas, comunidades, pueblos y nacionalidades hacia la justicia cuando estos individuos carezcan de la oportunidad de contratar su propia defensa técnica. De acuerdo a la Constitución del Ecuador de 2008 [4] en su artículo 192 manifiesta que la Defensoría pública prestara su servicio legal, técnico, oportuno, eficiente, eficaz y gratuito, en el patrocinio y asesoría jurídica de los derechos de las personas, en todas las materias e instancias.

Hablando en materia penal, y al menos haciendo un análisis teórico es en la Defensoría pública sobre la que recae el peso del patrocinio legal del procesado en todas las instancias que conlleve el proceso, se presupone que debe existir un asesoramiento oportuno del defensor público así como también una consecuente cooperación del procesado en cuanto a la información necesaria para sustentar la teoría de la Defensoría pública. No obstante como es de conocimiento de todos, en la práctica los presupuestos legales contenidos en la letra son totalmente distintos, puesto que en la mayoría de los casos los patrocinios puestos a consideración de la Defensoría son duramente criticados y cuestionados por el deficiente desempeño de su rol como defensores de los desprotegidos.

Los presupuestos lógicos que a mi criterio debe tener en cuenta el defensor público frente a una posible aplicación del procedimiento abreviado serían los siguientes: 1.- Análisis exhaustivo de los elementos de convicción tanto de cargo como de descargo que en la audiencia de calificación de flagrancia y formulación de cargos deberá presentar la Fiscalía, teniendo en cuenta criterios de valoración probatoria como legalidad, pertinencia, conducencia, nexo causal entre otros, mismo que servirán a la defensa técnica como elementos esclarecedores que le permitan llegar a la conclusión de la necesidad o no de poder solicitar a su defendido una posible aplicación del procedimiento abreviado y;

2.- En el supuesto de que previo a un análisis de los argumentos y elementos de convicción presentados por la Fiscalía, la defensa pública del procesado considerase oportuno y beneficioso una aplicación del procedimiento abreviado pues deberá entrar en una fase de asesoramiento para con el procesado en todo lo concerniente a la aplicación de este procedimiento especial, mismo que deberá hacerlo con un lenguaje sencillo y claro haciendo saber tantos las ventajas como las desventajas del mismo de tal manera que el procesado pueda comprender con claridad los mecanismos legales a los cuales su libertad pudiese acogerse de ser estrictamente necesario.

La Defensoría Pública cada año acoge un sin número de causas judicial en distintas materias, concretamente en el periodo comprendido del mes de enero hasta diciembre del 2019, la Defensoría pública dentro de su boletín estadístico anual del año 2019 presento los siguiente resultados concernientes al patrocinio de causas en materia penal por principales tipo de infracción.

En la práctica los delitos que normalmente suelen acogerse a este tipo de procedimiento especial son delitos de tráfico ilícito de sustancias catalogadas sujetas a fiscalización, delitos de violencia contra la mujer o miembros del núcleo familiar y delitos contra la integridad sexual y reproductiva, y más aún cuando los mismos fueron hallados en situación de flagrancia, lo que por ninguna razón debe ser causal de exclusión del debido proceso que les compete.

Dos son pues aquellos aspectos que a mi juicio son duramente criticables con base en los argumentos antes mencionados:

1.- El procedimiento abreviado en la actualidad se ha convertido en el recurrir normal y constante de los defensores públicos, puesto que como es de conocimiento de todos este tipo de procedimiento son usualmente mucho más aplicados por el patrocinio de una defensoría pública en aquellos delitos que involucran fuertes violaciones no únicamente a los derechos de las víctimas sino también a los del procesado y;

2.- El hecho de que los delitos que en su mayoría son patrocinados por la Defensoría pública y que por su naturaleza jurídica pueden ser objeto de aplicación del procedimiento abreviado, son aquellos delitos que detentan graves violaciones a los bienes jurídicos protegidos de las victimas así como de los cuales es titular la sociedad, la salud y la seguridad ciudadana. Esto implicaría por ende otro de los problemas dentro del procedimiento abreviado, mismo que si bien es cierto no es razón de análisis del presente artículo no obstante 
es importante su mención y es aquel que recae ya no en el deficientísmo del actuar de la Defensoría pública sino mas bien en el deficientísmo del Derecho Penal para con las víctimas quienes al buscar una plenitud o "justicia" en cuanto a la pena que le correspondiese al procesado como consecuencia de sus actos debidamente comprobados, se encuentra con el hecho de que a su infractor le corresponderá una pena reducida de la que penalmente le correspondiese por el hecho de haberse acogido a este tipo de negocio jurídico.

\section{E.- La crítica teórica confirmada en la práctica}

El proceso penal signado con el No. 09289-201700210 tiene relación con el delito de tráfico ilícito de sustancias catalogadas sujetas a fiscalización en mediana escala que contempla una pena privativa de libertad de cinco a siete años según el artículo 220 numeral 1 literal c) del COIP.

La noticia criminis de este caso se dio mediante un aviso telefónico al personal policial que se encontraba de patrullaje, el comunicado expuso la presencia de una persona que se encontraba en situación sospechosa y con una apariencia narco-dependiente, en ningún momento se menciona la existencia de algún cruce de manos, motivo por el cual el personal policial se movilizó al lugar y al encontrar a la persona que guardaba relación con las características brindadas por el aviso telefónico, se procedieron a acercar y a identificar como miembros de la Policía Nacional, consecuentemente se le encontró en su mano derecha 8 fundas plásticas de características sospechosas, motivo por el cual fue inmediatamente aprehendida y llevada a la Unidad de Polícia más cercana, previa a la emisión del certificado médico del galeno de turno, a esperas de realizarse la respectiva audiencia de calificación de flagrancia y formulación de cargos. Las sustancias fueron sujetas a la Prueba de Identificación preliminar Homologada dando como resultado Positivo para heroína con un peso bruto de 1.7 gramos y un peso neto de 0,9 gramos.

En la audiencia, a la procesada que responde a los nombres de Luisa F. (nombre protegido) asistida por un defensor público, se le formularon cargos por el delito de tráfico ilícito de sustancias catalogadas sujetas a fiscalización en mediana escala, por lo cual la Fiscalía determinó un tiempo de instrucción fiscal de 30 días y solicitud de la excepcional aplicación de prisión preventiva la cual fue concedida por el juzgador. Dentro de la instrucción fiscal se le realizó a la procesada el respectivo examen psicosomático y toxicológico, puesto que a mi juicio no siempre la persona detenida con cierta cantidad de gramos que no sobrepase de la lógica común debe ser categorizada y procesada como expen- dedora, puesto que se debe realizar una deducción para diferenciar el límite entre el mundo de un expendedor o comercializador y el de un consumidor o usuario al cual la Constitución le atribuye un problema de salud. En el caso concreto, a través del examen toxicológico se concluye en que la mujer presentaba una impresión diagnóstica de adicción a la droga (heroína) por lo que el perito sugirió que dicha mujer sea tratada en un centro especializado en problemas de adicción así como las pruebas en su sangre dieron negativo para marihuana y positivo para heroína y cocaína.

Aún con los antecedentes médicos antes expuestos, la causa se siguió sustanciando con normalidad y en la audiencia evaluatoria y preparatoria de juicio la Fiscalía más allá de toda evidente duda razonable respecto al cuadro de adicción solicita al defensor público de la procesada la posibilidad de la aplicación del procedimiento abreviado, negociando una pena privativa de libertad de tres años cuatro meses lo cual dio por finalizado el proceso con la aceptación voluntaria de la procesada y la autorización del respectivo juzgador.

Este proceso demuestra como varias de las críticas que se formulan respecto al procedimiento abreviado tienen sustento y se verifican en la práctica por lo siguiente:

1.- En el caso analizado el Informe Psicosomático y Toxicológico dio resultados concretos en cuanto a la existencia de una evidente impresión diagnóstica de adicción de la heroína por parte de la procesada, es decir, la procesada en relación con el cuadro diagnostico era una consumidora y adicta a la heroína, misma sustancia que se le encontró en su poder y que no se pudo comprobar por parte de los elaboradores del parte ni de la Fiscalía de que fue hallada flagrantemente en algún cruce de manos con otras personas. El artículo 364 de la Constitución del Ecuador del 2008 establece la no criminalización de las adicciones, al ser consideradas un problema de salud pública al cual se le acompañaran programas de información, prevención y control de consumo así como tratamiento y rehabilitación para las personas consideradas como consumidores ocasionales, habituales y problemáticos, aspecto que se le negó rotundamente a la persona procesada en el caso planteado.

2.- La Corte Constitucional dentro de la sentencia No. 7-17-CN/19 determino algunos puntos importantes aplicables a las causas por el presunto delito de tráfico de sustancias ilícitas. La Corte determinó que es importante entender que si bien es cierto la tabla sobre tenencia de sustancias expedidas por el Consejo Nacional de Sustancias Estupefacientes y Psicotrópicas CONSEP contiene los máximos de tenencia, en el evento de que 
una persona se encuentre en posesión de una cantidad superior a la establecida en la tabla, le corresponde al fiscal buscar los elementos de convicción de cargo y descargo a fin de que el juzgador los valore y de llegar a la etapa del juicio, las pruebas solicitadas, ordenadas, practicadas e incorporadas en el juicio deberán ser procesadas por los operadores de justicia. Es decir que a pesar de que a una persona se le encuentre en su poder una cantidad de sustancia superior a la estipulada en la tabla su estatus jurídico de inocencia frente a la catalogación de consumidor no se desnaturaliza, puesto que le corresponde a la Fiscalía establecer si esa persona adecuo íntegramente su conducta al verbo rector de comercializar.

3.- Se pone de relieve como en la mayoría de los casos, ni siquiera antes aquellos que conllevan intrínsecamente un problema de salud pública, la Fiscalía solicita la medida excepcional de prisión preventiva, sin siquiera poder sustentar con elementos de convicción objetivos la peligrosidad de que la persona proceda pudiese o no comparecer al proceso, sino que más bien este tipo de medidas se han convertido en nuestro sistema de justicia en un uso común y repetitivo por parte de los Fiscales en la mayoría de sus acusaciones, contraponiéndose contra todo presupuesto legal de excepcionalidad o de ultima ratio.

\section{III.METODOLOGÍA}

La metodología utilizada en el presente artículo científico es la metodología cualitativa, la cual parte del punto de determinar con claridad la problemática a analizar así la causa latente que provoca el efecto que se plantea a partir de una hipótesis, la cual al ser objeto de una investigación exhaustiva analítica, proporcionara el resultado deseado en el presente artículo, la metodología cualitativa es una de las dos metodología de la investigación que se esgrime en las ciencias prácticas, la cual se basa en los aspectos que no son susceptibles de cuantificación, cabe señalar que el estudio que se ha realizado es de carácter explicativo con una orientación cualitativa ya que en la misma he recogido mecanismos múltiples sobre diversos aspectos que abarca el tema planteado, para ello es menester determinar la causa sine qua non del problema, mismo que se explicará mediante argumentos objetivos, verdaderos y demostrables.

La razón última de la investigación cualitativa es desarrollar un resultado a el factor conducente a un fenómeno viviente en la problemática social, explicar bajo qué condiciones se origina y fundamental las razones que lo ocasionan, de tal manera que este tipo de investi- gación está encaminada a la comprobación de hipótesis de causa-efecto, a partir de la identificación y estudio de las misma. En el presente artículo científico se obtuvo información a través de la exploración documental bibliográfica, páginas web institucionales, consulta de libros de gran trascendencia doctrinal, obras de naturaleza jurídica, entrevistas a docentes, profesionales del Derecho en el libre ejercicio y personal administrativo de Unidades Judiciales.

\section{IV.RESULTADOS}

Con los antecedentes antes expuestos y analizados teniendo como sustento una serie de recopilaciones, teóricas, doctrinales, legales y jurisprudenciales el presente artículo científico sobre el Principio de presunción de inocencia frente a la aplicación del Procedimiento Abreviado en el Ecuador ha llegado a los siguientes resultados.

1.- Como consecuencia de la aplicación premeditada del Procedimiento Abreviado se incurre en una absoluta e insubsanable vulneratoria de derechos constitucionales, concretamente al destruir la situación jurídica de inocencia del imputado, careciendo de justificativo alguno la apología de constituir con este una celeridad procesal latente para la continuidad dinámica de la administración de justicia, puesto que como es de conocimiento público uno de los mayores problemas de la administración de justicia ordinaria, mismo que no ha variado con la aplicabilidad del procedimiento abreviado en los casi 20 años de su vida jurídica, es la lentitud procesal con la que se despachan las causas tanto en la Fiscalía como en las distintas Unidades Judiciales, Cortes o Tribunales de Justicia del Ecuador.

2.- Hasta antes de la llegada de la Ley Orgánica Reformatoria el Código Orgánico Integral Penal [5] el Procedimiento Abreviado se constituía en una peligrosidad latente en aquellas causas que se acogían a su naturaleza jurídica o beneficio, esto debido a que a lo largo de su transcendencia en el marco procesal a reflejado un sustancial agravio contra la constitucionalidad y seguridad jurídica de la sociedad, puesto que la mayoría de las conductas penalmente relevantes que podían ser objeto de acogerse al Procedimiento abreviado como consecuencia de no sobrepasar de una condena de 10 años de pena en abstracto, eran aquellas conductas que constituyen graves violaciones a los bienes jurídicos de las personas e inclusive a los bienes jurídicos del mismo procesado, y entre esas conductas ilícitas que se acogieron durante el periodo de laguna legal que contenía este procedimiento respecto de sus reglas, se encontraban los delitos contra la integridad sexual y reproductiva, secuestro y violencia contra la mujer o miembros del 
núcleo familiar. No obstante los delitos como tortura, aborto no consentido, robo sin muerte, instigación al suicidio entre otros, aún pueden acogerse a este tipo de procedimiento inconstitucional.

3. Se pone de manifiesto la ausencia de un mínimo de lógica jurídica respecto a los partícipes dentro de este tipo de proceso, como lo son inevitablemente los operadores de justicia, la Fiscalía, pero por sobre todo la defensa técnica pública o particular que patrocine al procesado, puesto que son cómplices del atropello a derechos supra-constitucionales del procesado al omitir el brindar una asesoría técnica que suponga un mínimo de seguridad jurídica para con su cliente al reprochar y negar este tipo de negociación de pena que pondrá en juego la libertad de su defendido, mientras que por el otro lado tenemos Fiscalía quien solo pretende llegar a una acelerada e injustificable sentencia condenatoria ejecutoriada más allá de toda presunción inocencia.

4.- El Procedimiento abreviado carece en lo absoluto de uno de sus presupuestos que sustentan su existencia en nuestro marco legal, esto es, el consentimiento o libre albedrío. En este sentido, es inexorable de que los operadores de justicia no solo se apeguen a los presupuestos de forma o solemnidades que instiguen a consentir en aplicar un procedimiento abreviado, sino que analicen haciendo un ejercicio de objetividad aquellas evidencias y elementos de convicción en los cuales se sustente el argumento fiscal, de tal forma que el consentimiento del procesado tanto en la aplicación del procedimiento abreviado así como en la aceptación del hecho que se le imputa, ponga de manifiesto la condición de que el individuo actúa con libre voluntariedad y concretamente que su admisión de responsabilidad es libre y transparente más no el resultado de factores coercitivos o de coacción psicológica. En ese mismo conducto de pensamiento resulta fundamental que la Fiscalía bajo ninguna circunstancia motiven o soliciten a la contraparte la aplicación del procedimiento abreviado, sino que sea la defensa la que luego del análisis del caso, solicite a la Fiscalía la posibilidad de someterse a este procedimiento especial

\section{V.CONCLUSIONES}

El negocio jurídico al cual le atribuyen la denominación de procedimiento abreviado es una maquina vulneradora de derechos constitucionales de carácter nacional y supranacional, puesto que pone en un estado mental de indefensión al imputado, al momento en el que acuerda una reducción de la pena siempre que este se exhorte de su libertad y de su derecho al debido proceso, al consentir en todos las acciones y omisiones que se le atribuyen, siendo este un tipo de tradición pro- cesal, en donde se da en venta la libertad y el debido proceso del justiciable, a cambio de una celeridad falseada del proceso. Con respecto a lo antes mencionado se usa como apología de todos los llamados procedimientos especiales al decir que resulta un punto acertado en cuanto a la celeridad procesal. De igual manera se ha concluido, que la aplicación de este procedimiento, atenta contra el principio procesal de la legitima defensa para con el procesado, el cual es de carácter inviolable e irrenunciable, pero al conllevarlo de manera capciosa por el sendero fraudulento del consentimiento del acto punible, este se ve despojado de todo intento posiblemente eficaz para extinguir totalmente los hechos de los que se le acusan, en otras palabras se menoscaba la normativa constitucional proclamada en el artículo 76 de la Constitución del Ecuador, así como el artículo 28 del Código Orgánico de la Función Judicial en lo pertinente a alcanzar a través del sistema procesal la realización de la justicia, pero de que utópica justicia hablamos, si se coadyuva psicológicamente al imputado para la sumisión del mismo en lo que respecta a hechos que jamás se probaran plenamente, debido a que por la naturaleza jurídica del procedimiento abreviado, se simplifican todas las etapas procesales en una única audiencia, de tal manera que las presuntas pruebas de cargo de la fiscalía, jamás serán objeto de contradicción por parte del procesado, puesto que este consiente de manera anticipada y guiada por la apología del fiscal, para que declare su culpabilidad y a manera de garantía, recibirá una reducción en la pena que se le impondrá.

Por lo tanto es indisponible el negociar con el derecho de defensa, como no se puede negociar con el derecho de la libertad.

\section{REFERENCIAS}

[1]A. Verdoodt, Declaración Universal de los Derechos del Hombre: nacimiento y significación., Editorial Mensajero, 1970.

[2]S. García Ramírez, «El debido proceso. Concepto general y regulación en la Convención Americana sobre Derechos Humanos,» Bol. Mex. Der. Comp., vol. 39, no 117, 2006.

[3]CDH, «Comité de Derechos Humanos. Observación general número 13.,» 1984. [En línea]. Available: https://tbinternet.ohchr.org/_layouts/15/treatybodyexternal/Download.aspx?symbolno $=\mathrm{INT} \% 2 \mathrm{fCCPR} \% 2 \mathrm{fGE}-$ $\mathrm{C} \% 2 \mathrm{f} 4721 \&$ Lang=en.

[4]Ecuador, "Constitución de la República del Ecuador,» 2008. [En línea]. Available: https://www.oas.org/ juridico/pdfs/mesicic4_ecu_const.pdf.

[5]R. Oficial, «Codigo Orgánico Integral Penal,» [En línea]. Available: https://tbinternet.ohchr.org/Treaties/ 
CEDAW/Shared\%20Documents/ECU/INT_CEDAW ARL_ECU_18950_S.pdf.

[6]J. Santos, «El debido proceso penal,» 2009.

[7]S. Zambrano, «El acceso a la justicia y tutela judicial efectiva en relación con la seguridad ciudadana en
Ecuador.,» Revista de Ciencias Sociales, 2015. [8]E. Zavala, Código Orgánico Integral Penal. Teoría del delito y sistema acusatorio., Editorial Murillo, 2014. [9]R. Vaca, Derecho Procesal Penal Ecuatoriano., Quito: Ediciones Legales., 2015. 